\title{
Spatial Distribution of Rice Sowing and Heading Dates in Southern China
}

\author{
Lin Wang \\ Jiangsu Key Laboratory of Agricultural \\ Meteorology \\ Nanjing University of Information \\ Science and Technology \\ Nanjing, PR China \\ linwangnuist@hotmail.com
}

\author{
Ting Li \\ Applied Meteorology College \\ Nanjing University of Information \\ Science and Technology \\ Nanjing, PR China \\ liting29320@sina.com
}

\author{
Yuanshu Jing \\ Jiangsu Key Laboratory of Agricultural \\ Meteorology \\ Nanjing University of Information \\ Science and Technology \\ Nanjing, PR China \\ jingyshu@163.com
}

Abstract-In this paper, we analyzed the spatial distribution of rice key phenology (sowing and heading) dates and the effect of critical temperature $\left(10^{\circ} \mathrm{C}\right.$ and $\left.20^{\circ} \mathrm{C}\right)$. Agricultural critical temperature was extracted from daily climate data. Spatial distribution characteristics of rice sowing and heading dates were analyzed with ArcGIS. Results showed that the popular dates of rice key phenology changed obviously in space, as well as that of critical temperature. The occurrence of $10^{\circ} \mathrm{C}$ was more closely related with rice sowing dates, and $20^{\circ} \mathrm{C}$ with heading dates. The dates of rice sowing and heading stages had similar spatial patterns with that of critical temperature, which meant agricultural critical temperature had great influence on rice development. Climatic gradients along the longitude and longitude directions were associated with that of rice development stages. Rice sowing and heading became late from south to north and also from inland to coast. There was also a large spatial difference in the response of rice phenology to critical temperature changes across the study region. The northwest Sichuan was mainly hilly region, so in this region rice phenology had strikingly different spatial patterns and also different response to critical temperature. The results of our research will provide scientific information for reasonable farming system arrangements and give guidance for future crop breeding.

Index Terms - Critical temperature, rice heading, sowing date, spatial distribution.

\section{INTRODUCTION}

Paddy rice is one of the main food resources in the world. China is the largest rice production country. In 2011, rice planting area is $3.0057 \times 107$ ha, occupying nearly $25 \%$ of the total cultivated area in China. Information on rice phenology is essential for evaluating crop yield, supporting decisions about water supply, and crop classification ${ }^{[1,2]}$.

Climate effect on rice involves food safety problems. Especially, agrometeorological critical temperature has close relation with crop growth and production. This temperature index has universal meaning indicating start, transition, or end of some phenology phenomena and farming activities ${ }^{[3]}$. There are more studies about critical temperature. Guo et al. reported that in Jiangxi province the beginning dates of $10^{\circ} \mathrm{C}$ were positively correlated with the vegetative stages for double-season early rice, but uncorrelated in reproductive stages ${ }^{[4]}$. Wang et al. found that the beginning dates of critical temperature had advancing tendency, while the end dates tended to delay in the southern margin of Qaidam Basin ${ }^{[5]}$. Obviously, ongoing warming trend has had measurable impacts on the development and production of field crops, but the size and extent of the impacts have differed spatially and temporally ${ }^{[6]}$.

Recently, there is a growing concern on the effect of warming on the phenology of cultivated crops due to its potential impact on crop yield and farming practices ${ }^{[7]}$. The majority of previous studies showed that increase in 
temperature shortened crop growing period, leading to reduced crop productivity ${ }^{[5,6]}$. In Germany, a shift in phenology of fruit trees and field crops due to increased temperature from 1961 to 2000 has been observed ${ }^{[7]}$. Shimono reported brief episodes of low temperature can greatly reduce seed set, thereby reduce rice yield, if they coincide with a brief critical period of only a few days during the booting stage ${ }^{[8]}$. Zhang et al. showed an average shortening of rice growth duration of 4.1-4.4 days for each additional increase in temperature over the full growth cycle $^{[9]}$.

Such diagnostic studies can be very helpful in improving models, and, consequently, have important implications for making appropriate adaptation measures and targeting future directions for crop breeding ${ }^{[6]}$. Responses of rice phenology to critical temperature on a country scale were more meaningful for evaluation of agriculture response to climate changes. However, most researches are concentrated on relationships between rice sowing and $10^{\circ} \mathrm{C}$ temperature. Little endeavor had been devoted to other stages. Temporal trend of temperature and crop phenology was research focus. Spatial distribution of crop phenology and its response to critical temperature was usually ignored.

In this paper, we analyzed the relationship between selected rice phenology and critical temperature. Our objective was to show whether there were significant spatial gradients in changes of rice phenology across Southern China, and whether these changes have had significant relationship with critical temperature variables.

\section{MATERIALS AND METHODS}

Rice phenological and daily temperature data in 2012 were downloaded from China Meteorological Data Sharing Service System. The administration map was downloaded from the National Fundamental Geographic Information System. In order to compare the dates conveniently and illustrate their spatial distribution clearly, we calculated and expressed the beginning date format as the day of the year (DOY). Five-day average method was utilized to extract the information of $10^{\circ} \mathrm{C}$ and $20^{\circ} \mathrm{C}$ beginning dates. And we used the popular stages of rice phenology, instead of the beginning date, as the latter records were too scarce.

Data from sparse meteorological stations were interpolated using ordinary kriging method to illustrate spatial distribution of rice phenology and to assess effect of critical temperature. Spatial analysis was performed using ArcGIS (ESRI Inc., v 9.3, Redlands, CA, USA). To examine their relationships, correlation analyses between phenology and temperature maps were also conducted.

\section{RESULTS}

\section{A. Statistical Analyisis}

The statistical parameters of the dates of rice phenology and critical temperature are listed in Table I. All the variables showed great variability. Rice sowing dates ranged from DOY $17\left(17^{\text {th }}\right.$, January) to DOY $165\left(13^{\text {th }}\right.$, June $)$, with mean value DOY 97 (6 $6^{\text {th }}$, April). And the minimum and maximum values of heading dates were DOY $70\left(10^{\text {th }}\right.$, March $)$, and $270\left(26^{\text {th }}\right.$, September), respectively, with mean value of DOY $206\left(24^{\text {th }}\right.$, July).

The beginning dates of $10^{\circ} \mathrm{C}$ showed the highest variablity judged from the largest coeffiecient of variability. It flunctuated from DOY 2 to 220, with a mean of DOY 75. The minimum, maximum, mean values of the beginning dates of $20^{\circ} \mathrm{C}$ were DOY 20,184 , and 127 , respectively.

TABLE I. STATISTICS OF THE BEGINNING DATES OF CRITICAL TEMPERATURE AND RICE PHENOLOGY

\begin{tabular}{|c|c|c|c|c|c|}
\hline \multirow{2}{*}{ Dates } & \multicolumn{5}{|c|}{ Statistical Parameters (DOY) } \\
\cline { 2 - 6 } & Mean & Minimum & Maximum & S.D. & C.V.(\%) \\
\hline $10^{\circ} \mathrm{C}$ & 75 & 2 & 220 & 34 & 45 \\
\hline $20^{\circ} \mathrm{C}$ & 127 & 20 & 184 & 23 & 18 \\
\hline Sowing & 97 & 17 & 165 & 23 & 24 \\
\hline Heading & 206 & 70 & 270 & 24 & 12 \\
\hline
\end{tabular}

The correlation coefficients among critical temperature and rice phenology dates are listed in Table II. They all passed the significant test at level $P<0.01$. Among them, the beginning dates of $10^{\circ} \mathrm{C}$ were much closer with rice sowing than with heading dates. Meanwhile, the beginning dates of $20^{\circ} \mathrm{C}$ had closer relationship with rice heading than with sowing dates. According to agricultural meteorology theory, daily temperature reaching $10^{\circ} \mathrm{C}$ stably is suitable for thermophilous crop seedling to begin growth in general. Thus, the beginning date of $10^{\circ} \mathrm{C}$ is considered as the start of rice sowing in spring. And the days with temperature above $10^{\circ} \mathrm{C}$ are evaluated as the 
growth stages for rice. Meanwhile, $20^{\circ} \mathrm{C}$ is the safety temperature index for rice heading and flowering ${ }^{[3]}$.

TABLE II. CORRELAITON COEFFICIENTS AMONG CRITICAL TEMPERATURE AND SELECTED RICE PHENOLOGY

\begin{tabular}{|c|c|c|}
\hline \multirow{2}{*}{ Rice Phenology } & \multicolumn{2}{|c|}{ Critical Temperature } \\
\cline { 2 - 3 } & $\mathbf{1 0 ^ { \circ }} \mathbf{C}$ & $\mathbf{2 0 ^ { \circ }} \mathbf{C}$ \\
\hline Sowing & $0.76^{* *}$ & $0.63^{* *}$ \\
\hline Heading & $0.74 * *$ & $0.79^{* *}$ \\
\hline
\end{tabular}

**. Significant level at $P<0.01$

\section{B. Spatial Distribution of Climate Factors}

Fig.1 illustrated the spatial distribution of beginning dates of $10^{\circ} \mathrm{C}$ and $20^{\circ} \mathrm{C}$ critical temperature. Critical $10^{\circ} \mathrm{C}$ had changing gradients from south to north, parallel to the latitude direction (Fig. 1 a). In the south regions with lower latitude, $10^{\circ} \mathrm{C}$ occurred earlier, especially in Yunan, and Hainan provinces. In the north, $10^{\circ} \mathrm{C}$ occurred later. Beginning dates of $10^{\circ} \mathrm{C}$ appearing from to the $29^{\text {th }}$ February to the $9^{\text {th }}$ April (DOY 60-100) occupied the largest percentage (69\%) of the total area. Besides, there was significant changing trend along the longitude direction, especially in the north regions. From coast to inland, the beginning dates of $10^{\circ} \mathrm{C}$ experienced advancing tendency. However, in the northwest Sichuan, the beginning time of $10^{\circ} \mathrm{C}$ was the latest (DOY 100-220).
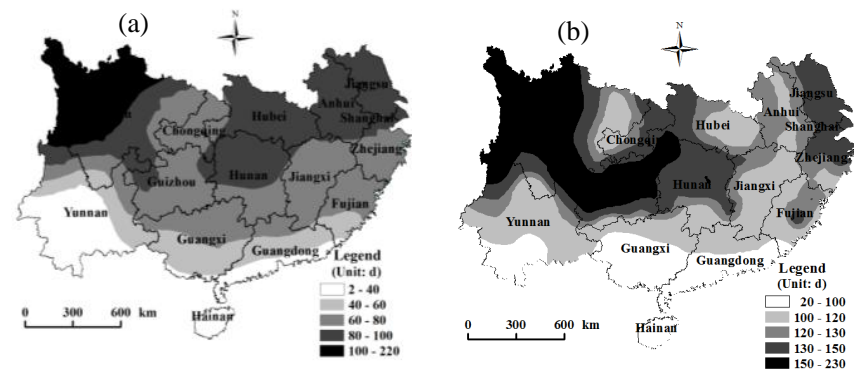

Fig. 1. Spatial distribution of beginning dates of critical temperature $\left(\mathrm{a}, 10^{\circ} \mathrm{C}\right.$;

$$
\text { b, } \left.20^{\circ} \mathrm{C}\right) \text {. }
$$

Similarly, the beginning dates of $20^{\circ} \mathrm{C}$ had obvious latitude gradient (Fig. 1 b). From south to north, $20^{\circ} \mathrm{C}$ appeared delaying trend. In the north, there were also meridional gradients. The coastal regions, such as Jiangsu, Shanghai, and the north of Zhejiang, had later $20^{\circ} \mathrm{C}$ beginning dates. And the latest date for the beginning of $20^{\circ} \mathrm{C}$ occurred in the Sichuan and west Guizhou. Regions where beginning dates of $20^{\circ} \mathrm{C}$ occurring from $9^{\text {th }}$ April to $2^{\text {th }}$ May (DOY 100-150) occupied the largest area percentage (68\%). These regions mainly located in the central and the east parts.

\section{Spatial Distribution of Selected Rice Phenology}

Fig.2 (a) showed that rice sowing dates had also obvious spatial variability. There were both zonal and meridional changing trends. From south to north, sowing dates tended to delay. Meanwhile, from coast to inland, rice sowing became earlier. The coastal regions in the northeast had the latest sowing dates, and the earliest occurred in the south of study region. In over 55 percentage area, rice seeds were sowed during the period from the $10^{\text {th }}$ March to the $9^{\text {th }}$ April (DOY 70-100).

Rice sowing dates had similar spatial characteristics with that of $10^{\circ} \mathrm{C}$, which meant rice sowing time was arranged according to critical temperature. Hainan and south Yunnan sowed rice seeds earlier than other regions, related to their early arrival at $10^{\circ} \mathrm{C}$ in daily mean temperature.

The spatial patterns of heading dates (Fig. 2 b) were similar to that of sowing and showed consistent characteristics with $20^{\circ} \mathrm{C}$, changing gradually from north to south and from coast to inland. The northeast region had the latest heading dates. Meanwhile, rice in the Hainan, south Guangdong, and Guangxi provinces had the earliest heading dates. Most regions where rice began to head and flower in the $18^{\text {th }}$ July to $27^{\text {th }}$ August (DOY 200-240) occupied 64 percentage of the total area, located in the central part.

In general, spatial distribution of critical temperature and rice sowing, heading dates were coherent. Most central regions had relative homogeneous critical temperature and correspondingly similar rice phenology dates. But response of rice phenology to critical temperature was variable in space. There were time span between the dates of critical temperature and rice phenology. Pritchard and Amthor once noted that the expected temperature increase will not be geographically and seasonally uniform around the world ${ }^{[10]}$. Landform, location from coastline, local climate, rice cultivars might cause this difference. And of course, the use of popular stages of rice phenology also brought about great influences on their relationship. The later critical temperature beginning dates in the coastal regions were probably caused by the large specific heat capacity of sea water. Meanwhile, northwest Sichuan was hilly region, isolated and different from other plain area. Once, 
critical temperature was reached, rice seeds would be sowed as soon as possible. And in hilly region, rice had short growth length, in order to avoid cold hazards in rice growth. Early ripening varieties were chosen to be planted here.
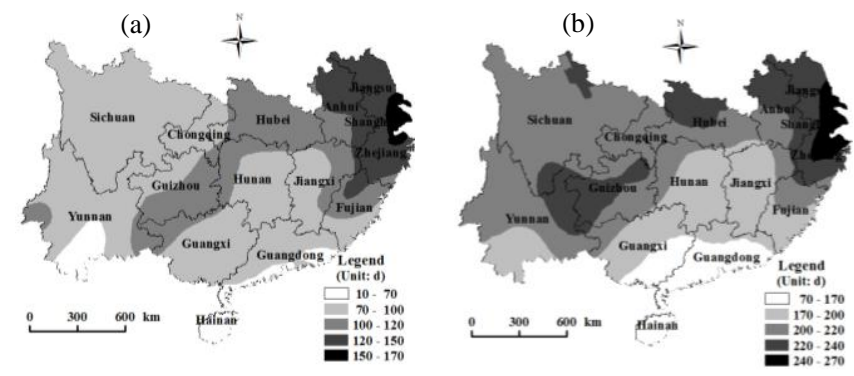

Fig. 2. Spatial distribution of selected rice phenology (a, sowing; $b$, heading)

\section{CONCLUSION}

We extracted rice phenology and critical temperature dates information from crop phenology records and daily temperature data. Spatial patterns of these variables were analyzed. There were close relationships between them. Rice sowing and heading dates had obvious spatial variability, similar with that of $10^{\circ} \mathrm{C}$ and $20^{\circ} \mathrm{C}$ temperature beginning dates Firstly, rice phenology appeared zonal spatial characteristics, delaying from south to north. Secondly, from coast to inland, critical temperature and rice phenology showed advancing trend. Thirdly, there was discrepancy between critical temperature and rice phenology dates. Because of China's large size and range of agro-ecological conditions, sensitivity of rice phenology could vary considerably, leading to complex spatial patterns of response.

In future, we will further our researches by analyzing long time-series of rice phenology and critical temperature data, in order to stabilize our research results and prove rice growth spatial and temporal variability according to temperature changes.

\section{ACKNOWLEDGMENT}

The study was supported by the project funded by the Jiangsu Key Laboratory of Agricultural Meteorology (JKLAM201203), the Special Fund for Public Welfare Meteorological Industry (GYHY200906022), and the Six Great Talents Peak Plan of Jiangsu, China (NY-038).

\section{REFERENCES}

[1] M. Digkuhn, and P.L.Gal, "Effect of drainage date on yield and dry matter partitioning in irrigated rice," Field Crops Research, vol 46, pp. 117-126. 1996.

[2] B.A.M. Bouman, M.J. Kropff, T.P.Tuong , M.C.S. Wopereis, H.F.M. ten Berge, H.H. van Laar, ORYZA2000: Modeling Lowland Rice. Manila, Philippines: International Rice Research Institute. 2001.

[3] J. Xiao, B. Mu, and F. Hu, Agricultural Meteorology, Beijing: Higher Education Press, 2009, pp. 63-68.

[4] R. Guo, S. Liu, and X. Du, "Daily variation of beginning date of 10eand its impacts on phenological period of double-season early rice in Jiangxi”, Chinese Journal of Agrometeorology, vol 32, pp. 12-16, 2011.

[5] F. Wang, G. Qi, X. Guo, and B. Li, "Climatic Change of Agricultural Critical Temperature in the Southern Margin of Qaidam Basin," Journal of Arid Meteorology, vol 27, pp. 227-231, 2009.

[6] F. Tao, M. Yokozawa, Y. Xu, Y. Hayashi, and Z. Zhang, "Climate changes and trends in phenology and yields of field crops in China, 1981-2000," Agricultural and Forest Meteorology, vol 138, pp. 82-92, 2006.

[7] F.M. Chmielewski, A. Müller, and E. Bruns, "Climate changes and trends in phenology of fruit trees and field crops in Germany1961-2000," Agricultural and Forest Meteorology, vol 121, pp. 69-78 2004.

[8] H. Shimono, "Earlier rice phenology as a result of climate change can increase the risk of cold damage during reproductive growth in northern Japan," Agriculture, Ecosystems \& Environment, vol 144, pp.201-207, 2011.

[9] T. Zhang, Y. Huang, and X.Yang, "Climate warming over the past three decades has shortened rice growth duration in China and cultivar shifts have further accelerated the process for late rice,” Global Change Biology, vol 19, pp. 563-570, 2013.

[10] S.G. Pritchard, and J.S. Amthor, Crops and Environmental Change. Food Production Press, New York, NY. 2005. 